\title{
CORRIGENDUM
}

\section{Voriconazole or itraconazole for antifungal prophylaxis in patients with grade II-IV acute or extensive chronic graft-versus-host disease}

\author{
D Marks, C Kibbler, G Cook, A Pagliuca, A Reisman, P Miller, M Kantecki and H Schlamm,
} on behalf of the IMPROVIT Study Group

Bone Marrow Transplantation (2010) 45, 1578; doi:10.1038/bmt.2010.215

36th Annual Meeting of the European Group for Blood and Marrow Transplantation

26th Meeting of the EBMT Nurses Group

9th Meeting of the EBMT Data Management Group

2nd EBMT Quality Management Meeting

Vienna, Austria, 21-24 March 2010

Correction to: Bone Marrow Transplant 45: S78-S327; doi:10.1038/bmt.2010.41

Since the publication of this paper, an error has been identified in abstract P723 located on pages S209-S210 entitled 'Voriconazole or itraconazole for antifungal prophylaxis in patients with grade II-IV acute or extensive chronic graft-versus-host disease'.

The third sentence in the Results section currently reads: 'Mean time to first report of GvHD was 49.6 for VOR vs 37.6 days for ITR $(P=0.067)$.' However, the sentence should correctly read:

'Mean time to first report of GvHD was 127.8 for VOR vs 85.2 days for ITR $(P=0.823)$.'

The authors would like to apologize for any confusion this may have caused. 